\title{
Perillyl Alcohol in Solid Lipid Nanoparticles (SLN-PA): Cytotoxicity and Antitumor Potential in Sarcoma 180 Mice Model
}

Luciana N. Andrade ${ }^{1}$, Mariana S. S. Cavendish ${ }^{2,3}$, Salvana P. M. Costa ${ }^{2,3}$, Ricardo G. Amaral ${ }^{1}$, Cristiane B. Corrêa ${ }^{1}$, Douglas S. Oliveira ${ }^{1}$, Margreet Morsink ${ }^{4,5,6}$, Evren H. Gokce ${ }^{7}$, Ricardo L. C. de Albuquerque Junior ${ }^{2,3}$, Eliana B. Souto ${ }^{8,9}$, Patrícia Severino ${ }^{2,3,4,10 *}$

${ }^{1}$ Federal University of Sergipe (UFS), Avenida Governador Marcelo Déda, Lagarto - SE, 49400-000, Brazil

${ }^{2}$ Laboratory of Nanotechnology and Nanomedicine (LNMed), Institute of Technology and Research (ITP) Av. Murilo Dantas, 300, 49010-390 Aracaju-SE, Brazil

${ }^{3}$ University of Tiradentes (Unit) Av. Murilo Dantas, 300, 49010-390 Aracaju-SE, Brazil

${ }^{4}$ Division of Engineering in Medicine, Department of Medicine, Harvard Medical School, Brigham and Women's Hospital, Cambridge, Massachusetts 02139, United States

${ }^{5}$ Translational Liver Research, Department of Medical Cell BioPhysics, Technical Medical Centre, Faculty of Science and Technology, University of Twente, Enschede, The Netherlands

${ }^{6}$ Department of Developmental BioEngineering, Faculty of Science and Technology, Technical Medical Centre, University of Twente, Drienerlolaan 5, 7522 NB Enschede, The Netherlands

${ }^{7}$ Department of Pharmaceutical Technology, Faculty of Pharmacy, Ege University, 35100 Bornova-Izmir, Turkey

${ }^{8}$ Faculty of Pharmacy, University of Coimbra, Pólo das Ciências da Saúde, Azinhaga de Santa Comba, 3000548 Coimbra, Portugal

${ }^{9}$ CEB - Centre of Biological Engineering, University of Minho, Campus de Gualtar 4710-057 Braga, Portugal ${ }^{10}$ Tiradentes Institute, 150 Mt Vernon St, Dorchester, Massachusetts 02125, United States

\section{Graphical abstract}<smiles>C=C(C)C1CC=C(CO)CC1</smiles>

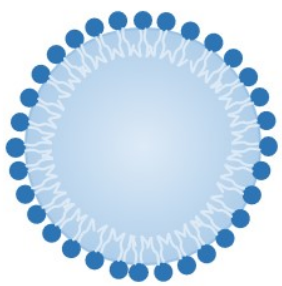

Perillyl Alcohol

Solid Lipid Nanoparticle
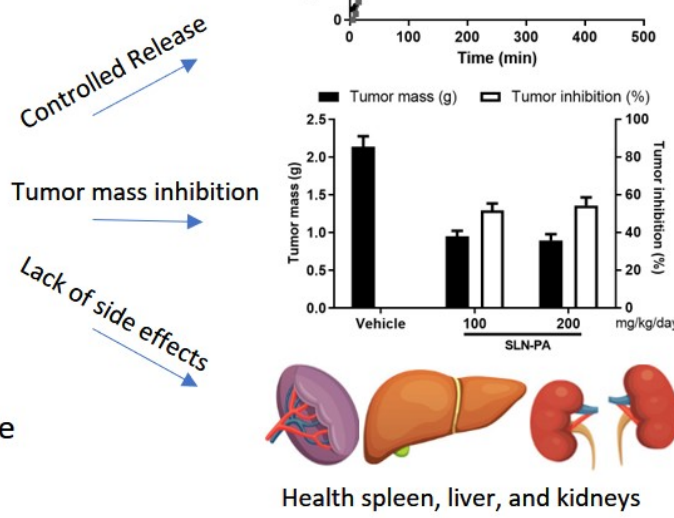

\section{Abstract}

Cancer is a group of diseases characterized by the uncontrolled growth of cells. These cells invade organs and tissues by extension or direct dissemination and can spread to other regions of the body. Nanomedicine offers many possibilities to prevent the spread of cancer tissue and help cure the disease.

* Eliana B. Souto, Department of Pharmaceutical Technology, Faculty of Pharmacy, University of Coimbra, Pólo das Ciências da Saúde, Azinhaga de Santa Comba, 3000-548 Coimbra, Portugal, Tel.: +351 239 488 400; E-mail: ebsouto@ff.uc.pt;

Patrícia Severino, Institute of Technology and Research (ITP) and Tiradentes University (UNIT) - Aracaju / SE, Av. Murilo Dantas, 300. Farolândia - Aracaju-SE. CEP 49.032-490 + +55 (79) 3218-2190 (R-2599). Email: patricia_severino@itp.org.br 
In this work, solid lipid nanoparticles (SLN) were used to encapsulate perillyl alcohol (PA), a volatile monoterpene with proven anticancer activity. Encapsulation of PA into SLN (SLN-PA) is expected to promote controlled release, increase PA bioavailability, and impair the volatility of the monoterpene.

SLN-PA prepared by high-shear homogenization showed average particle diameter around $254 \mathrm{~nm}$, polydispersity index $\sim 0.35$, zeta potential $\sim-14.7 \mathrm{mV}$, and encapsulation efficiency $84.6 \%$. Scanning electron microscope analysis revealed a decrease in crystallinity, suggesting the encapsulation of PA in the SLN, confirming the spherical shape and the loading of the monoterpene in the SLN. In vitro cytotoxicity assays against murine fibroblasts (L929) showed that SLN-PA in both treated doses did not induce any cytotoxicity on non-tumoral cells. In vivo antitumor effect of the SLN-PA was evaluated in sarcoma 180-transplanted mice. The in vivo results demonstrated a significant tumor inhibition rate of 51.76 and $54.49 \%$ via intraperitoneal application of SLN-PA at doses of 100 and $200 \mathrm{mg} / \mathrm{kg} / \mathrm{day}$ (p < 0.05), respective when compared to the negative control (dimethyl sulfoxide). Adverse side effects of SLN-PA were not noticed in the liver, the kidney, or spleen tissue. The developed SLN-PA can be considered as a safe approach for site-specific antitumor effect in vivo, reinterpreting new nanoparticles-based cancer therapy.

\section{Keywords:}

Perillyl alcohol; monoterpenes; solid lipid nanoparticles, antitumor, sarcoma 180 , toxicity

\section{Introduction}

Current cancer treatment options include surgery, chemotherapy, and radiation therapy [14]. Even with these existing treatment modalities, cancer still causes more deaths than all coronary heart diseases or strokes, with increasing world estimates for the coming decades $[5,6]$. Consequentially, the use of naturally derived substances for cancer treatment has been gaining attention in recent years for the development of new therapeutic approaches.

Monoterpenes are being widely studied among the natural compounds because of their known pharmacological properties, such as antifungal, antibacterial, antioxidant, anticancer, antiarrhythmic, anti-aggregating, local anesthetic, antinociceptive, anti-inflammatory, antihistaminic, and anti-spasmodic activities [710]. Perillyl alcohol (PA) is a phenolic monoterpene present in several essential oils. In contrast, several studies highlight antiproliferative activity for in vitro human tumor cell lines, its antitumor activity in vivo, and it can be found in phase II clinical studies for the treatment of glioblastomas [11-13]. However, the use of PA in the pharmaceutical industry encounters some disadvantages, as the compound is volatile [14]. Nanotechnology can thus offer an efficient approach to minimize these limitations. Moreover, it can potentially improve the efficacy of traditional drug delivery and adjust the pharmacokinetics and administration, thereby reducing adverse effects $[15,16]$.

Solid lipid nanoparticles (SLN) emerged in the 1990s as promising nanocarriers for cancer therapy. They offer several advantages, such as low toxicity [17-19], high bioavailability of drugs, and the capacity to load a range of chemically different drugs. It enables the transport across physiological barriers, improves the delivery of drugs to the target cell, can escape mechanisms of resistance, and proves to be effective against breast, lung, colon, liver, and brain tumors [20,21]. Besides, SLN is reported to be biocompatible and safe carriers for a range of administration routes, while their solid matrix contributes to the controlled release of loaded drugs. Thus, SLN can be a promising nanoplatform for the incorporation of antitumor drugs with, such as PA, with the aim of improving its bioavailability, efficiency, and biosafety profile, while reducing its volatility [22-24].

In this work, we aimed at developing SLN for the loading of PA as an innovative, biocompatible, and biosafe nanoparticle-based approach for chemotherapeutic treatment. Monoterpene release from SLN, physicochemical properties, bioavailability, cytotoxicity, and antitumor effect in a sarcoma 180 mice model have been studied.

\section{Materials and methods}

\subsection{Materials}

Cetyl palmitate was donated as a gift from Croda (Campinas, Brazil); PA and Poloxamer ${ }^{\circledR}$ 407 were purchased commercially from SigmaAldrich (Taufkirchen, Germany). If not otherwise stated, all other reagents were supplied from Sigma-Aldrich (St. Louis, Missouri, USA). Double-distilled water was used after filtration in a Millipore system (home supplied). 


\subsection{SLN preparation}

SLN were developed by high-shear homogenization [22]. Briefly, the aqueous phase consisted of the aqueous solution, the surfactant Poloxamer ${ }^{\circledR} 407(0.0025 \mathrm{~g} / \mathrm{mL})$, and the oil phase consisted of cetyl palmitate dissolved in ethanolic solution $(0.0125 \mathrm{~g} / \mathrm{mL}, \mathrm{w} / \mathrm{mL})$. Both phases were homogenized by magnetic stirring for 24 hours (Marte Científica, São Paulo, Brazil), at room temperature $\left(25^{\circ} \mathrm{C}\right)$. After stirring, both phases were heated in a water bath at $70^{\circ} \mathrm{C}$, and the oil phase was poured into the aqueous phase and homogenized using Ultraturrax ${ }^{\circledR}$ (IKA T18, Staufen_im Breisgau, Germany) at a speed of $22000 \mathrm{rpm}$ for 5 minutes. The formulation was cooled down in an ice bath and filtered through a Millipore filter (Merck KGaA, Darmstadt, Germany) with a pore size of 0.45 $\mu \mathrm{m}$, followed by $0.22 \mu \mathrm{m}$. For the encapsulation of the PA, the same procedure was used by adding the monoterpene to the oil phase before homogenization.

\subsection{Particle size, polydispersity index, and zeta potential}

The average size, polydispersity index, and zeta potential of SLN were determined by photon correlation spectroscopy (Malvern Zeta sizer, Nano Z-S; Malvern Instruments, Worcestershire, United Kingdom). The analyses were performed at an angle of 90 degrees at $25^{\circ} \mathrm{C}$ and a $633 \mathrm{~mW}$ He-Ne laser with a wavenumber of $632.8 \mathrm{~nm}$. An aliquot with a dilution factor of 1: 100 was taken at half the height of the cuvette and measured in triplicate.

\subsection{Encapsulation efficiency (EE \%)}

The formulations were centrifuged (DIK6750 Centrifugal Mixer, Saitama, Japan) at $16000 \mathrm{rpm}$ for 1 hour at room temperature. The drug quantification was performed by ultraviolet spectrophotometry at $245 \mathrm{~nm}$, using a UV FEMTO 800 XI (FEMTO Spectrophotometer, São Paulo, Brazil) against a validated calibration curve. The EE \%) was calculated using the following equation [25]:

$$
E E(\%)=\frac{\text { Total amount of } P A-P A \text { in supernatant }}{\text { Total amount of } P A}
$$

\subsection{Thermal analysis}

The thermogravimetry (TG) analysis was performed in a thermo-balance (Shimadzu TG-60, Kyoto, Japan) in the range of $25-500^{\circ} \mathrm{C}$, under nitrogen atmosphere $\left(\mathrm{N}_{2}\right)$, with a gas flow rate of $50 \mathrm{~mL} \mathrm{~min}{ }^{-1}$, and a heating rate of $10^{\circ} \mathrm{C}$ $\mathrm{min}^{-1}$. Differential scanning calorimetry (DSC) curves (DSC 2010 TA Instruments, Mettler Toledo, Columbus, Ohio, United States) were scanned in the range $0-350^{\circ} \mathrm{C}$, under a nitrogen atmosphere $\left(\mathrm{N}_{2}\right)$, with a gas flow rate of $50 \mathrm{~mL}$ $\mathrm{min}^{-1}$, and a heating rate of $10^{\circ} \mathrm{C} \mathrm{min}^{-1}$. The aluminum sample of both TG and DSC held contained 6.0 to $8.0 \mathrm{mg}$ of sample [22].

\subsection{Wide-angle X-ray diffraction (WAXD)}

The X-ray diffractograms of the samples were obtained on a diffractometer (Shimadzu XRD7000, Kyoto, Japan), operating in scanning mode with CUK $\alpha$ radiation $(\lambda=1.5418 \AA)$, voltage $40 \mathrm{kV}$, current $30 \mathrm{~mA}$, scanning speed $(2 \theta)=0.01 \mathrm{~min}^{-1}$, with an acquisition time of 5 seconds for each step. The calibration of the scanning angle ( $2 \theta)$ was done with polycrystalline silicon.

\subsection{Transmission electronic microscopy}

Transmission electron microscopy images were obtained using a transmission electron microscope (TEM-MSC JEOL 210, Tokyo, Japan), electron diffraction analysis of the selected area (SAED) of the SLN, and SLN-PA samples was performed using the microscope software.

\subsection{In vitro drug release}

The in vitro release study was performed using the dialysis method, adapted from Andrade et al. [26]. Precisely, $10 \mathrm{~mL}$ of the SLN-PA solution was placed in the dialysis bag $(5 \mathrm{~cm}$ long, $25 \mathrm{~mm}$ wide, and $16 \mathrm{~mm}$ in diameter InLab, Brazil) and surrounded by $40 \mathrm{~mL}$ of phosphate buffer at $37 \pm 1{ }^{\circ} \mathrm{C}, \mathrm{pH} 7.0 \pm 0.4$, under stirring at $200 \mathrm{rpm}$. These releasing processes were conducted over 8 hours, and $200 \mu \mathrm{L}$ of the aliquots were collected and filtered at various time points $(100,200,300,400$, and $500 \mathrm{~min})$ with medium replacement to be quantified by UV- 
Vis spectrophotometry. The release kinetics was analyzed according to different mathematical models, namely, Baker and Lonsdale, Korsmeyer-Peppas, Hixon and Crowell, Higuchi, and First Order.

\subsection{Cell viability}

Cell viability was assessed by the colorimetric method using methyl-thiazolyl-tetrazolium (MTT). The L929 murine fibroblast cell line was provided by LGC Standards SLU, Barcelona, Spain. Cells were grown in cell culture bottles ( $75 \mathrm{~cm}^{3}, 250 \mathrm{~mL}$ volume), using RPMI 1640 and supplemented with $10 \%$ fetal bovine serum and $1 \%$ antibiotics (penicillin/streptomycin) as media. This cell line was used as a model in testing of free PA, SLN, and SLN-PA at a concentration of $30 \mu \mathrm{g} / \mathrm{mL}$ each and based on the ISO 10993-5 [27]. L929 cells were seeded in 96 -well culture plates $\left(2 \times 10^{4}\right.$ cells/well $)$, grown in Dulbecco's modified Eagle's medium containing $\mathrm{NaHCO}_{3}\left(1.2 \mathrm{~g} \mathrm{~L}^{-1}\right)$, ampicillin $\left(0.025 \mathrm{~g} \mathrm{~L}^{-1}\right)$, streptomycin $\left(0.1 \mathrm{~g} \mathrm{~L}^{-1}\right)$ and supplemented with $10 \%$ FBS. After contact with PA, SLN, and SLN-PA, the cells were incubated for 24 hours $\left(37^{\circ} \mathrm{C}\right.$ in a $5 \% \mathrm{CO}_{2}$ atmosphere), centrifuged, and MTT $\left(5 \mathrm{mg} \mathrm{mL}^{-1}\right)$ was added. After 3 hours of incubation with MTT $\left(37^{\circ} \mathrm{C}\right.$ in a $5 \% \mathrm{CO}_{2}$ atmosphere), the formazan product was dissolved in $80 \mu \mathrm{L}$ dimethyl sulfoxide (DMSO) for 10 minutes. Then the absorbance was measured using a microplate reader at $570 \mathrm{~nm}$. The tests were performed in quadruplicate.

\subsection{Antitumor effect}

\subsubsection{Animals}

The experimental protocol was submitted and approved by the Animal Care and Use Committee (CEUA) at Tiradentes University CEUA under registration number No. 021116R. Forty Swiss mice (female, weight varying between 25 and $30 \mathrm{~g}$ ) were obtained from the central biotherium of Tiradentes University, Brazil. The animals were housed and kept under a temperature-controlled room $\left(22-25^{\circ} \mathrm{C}\right)$, with $12: 12$ hour light-dark cycle and free access to food and water. Sarcoma 180 (S180) cells were obtained from the Federal University of Sergipe. The donor animal was anesthetized via intraperitoneal and euthanized in a $\mathrm{CO}_{2}$ chamber. After, $0.5 \mathrm{~mL}$ of ascitic tumor cells were aspirated from the animal's abdominal cavity so that viable cells were selected using the trypan blue exclusion method [28]. $2 \times 10^{6}$ cells $/ 0.5$ $\mathrm{mL} /$ mouse was inoculated into the recipient animals, subcutaneously, in the animal's left axillary region [28-30]. After 24 hours of inoculation, intraperitoneal (i.p.) treatments were started to assess the effect of drugs on tumor growth, one application a day for seven consecutive days. The animals were split into 4 groups $(\mathrm{n}=06)$ denominated empty SLN (vehicle), SLN-PA (100 mg kg-1 per day), SLN-PA (200 $\mathrm{mg} \mathrm{kg}^{-1}$ per day), and 5-FU-25 $\mathrm{mg} \mathrm{kg}^{-1}$ per day (positive control). After $24 \mathrm{~h}$ the last day of treatment, the animals were euthanized by induction in a $\mathrm{CO}_{2}$ chamber, and the tumors were removed.

\subsubsection{Toxicological evaluation - biochemi- cal and immunological parameters}

For the quantification of the biochemical parameters (urea, creatinine, aspartate aminotransferase) AST, and alanine aminotransferase (ALT), the blood of the mice was subjected to centrifugation for 10 minutes at $3500 \mathrm{rpm}$ to obtain plasma. Biochemical and hematological analysis was carried out using specific kits for the automatic biochemical analyzer Cobas Mira Plus $^{\mathrm{TM}}$ and the automatic cellular hematology analyzer Animal Blood Counter Vet. Blood extensions were stained manually and analyzed using an optical microscope.

\subsubsection{Histopathological evaluation of or-} gans

After weighing the spleen, liver, kidneys, and tumor, tissues were sectioned, fixed in buffered formalin ( $10 \%$ formaldehyde solution) for histopathological analysis. Briefly, samples went through a dehydration series of increasing amounts of alcohol (70 to $100 \%$ ), diaphanization in xylol, impregnation, and inclusion in paraffin, according to established protocols. In a semi-automatic rotary microtome (American Optical ${ }^{\circledR}$ ), the tissue fragments embedded in paraffin were sectioned at a thickness of $3.0 \mu \mathrm{m}$ and subsequently subjected to hematoxylin-eosin staining, and then examined using an optical microscope.

\subsection{Statistical analysis}

The results are reported as the mean \pm standard error of the mean, and for multiple comparisons of the data, analysis of variance was performed (ANOVA), followed by the Student Newman Keuls or Dunnet post-test using the 
GraphPad Prism version 7.0 program (GraphPad Software, San Diego, CA, USA).

\section{Results and Discussion}

Several drugs currently used in clinical practice exhibit high toxicity and lipophilicity, low bioavailability, and significant instability in biological systems [26]. Given these limitations, efforts are being put forward to improve targeted delivery of drugs exploiting innovative techniques (e.g., micro/nanoencapsulation) to enhance their pharmacological effects while also ensuring safety for patients undergoing treatment. In this context, continuing the work of Cavendish et al. [22] and considering the antitumor effect of the PA described by Andrade et al. $[28,31]$, the present study aimed to develop, characterize and evaluate the in vitro and in vivo activity of the SLN loading PA (SLNPA).

The particle size of SLN was $489.95 \pm 0.23$ $\mathrm{nm}$, and the SLN-PA was $254.77 \pm 8.10 \mathrm{~nm}$. The size is a critical parameter to ensure the quality (and safety) of nanoparticles for nanomedical applications [17, 32]. Nanoparticles of around $200 \mathrm{~nm}$ in size can easily leak through the tissue fenestrae into the tumor and be retained [33], resulting in enhanced permeability and retention (EPR) effect. This EPR effect is now becoming the gold-standard in cancer treatment for which nanoparticles are instrumental for targeted drug delivery. The polydispersity index of SLN and SLN-PA werewas 17 \pm 0.001 and $0.350 \pm 0.016$, respectively. Values below 0.3 indicate homogeneity of the formulation, which reveals a high stability of SLN [34]. The zeta potential, as an indirect measure of the surface electrical charge of the particles, results from the interaction of the charges of molecules present in the SLN with the surrounding and can be used to predict the nanoparticles risk aggregation under storage. The zeta potential can be attributed to the surfactants used to stabilize the particles, while the ideal zeta potential values are reported to be around $|30 \mathrm{mV}|[35]$. The zeta potential results obtained for SLN and SLN-PA were $-17.0 \pm 0.50$ and $-14.7 \pm 1.21 \mathrm{mV}$, respectively. The slightly negative values are attributed to the concentration of the non-ionic surfactant Polaxamer ${ }^{\circledR} 407$, resulting in the reduction of the absolute values of the surface electrical charge. Although reducing the zeta potential, these hydrophilic non-ionic polymers (e.g., poloxamers) also contribute to reduce the risk of particle aggregation as they are placed onto the surface of the particles promoting stereochemical hindrance. In a study by Sioli Montoto et al. [36], the developed SLN showed zeta potential values between -2.4 and $-6.3 \mathrm{mV}$, which could compromise the electrostatic stability of SLN. However, the presence of the non-ionic surfactant (Pluronic ${ }^{\mathbb{B}} \mathrm{F} 68$ ) promoted the long-term stability from the hydrophilic hindrance surrounding the particles.

Both the lipid crystallinity and drug lipophilicity influenced the EE of PA in SLN. EE of SLN-PA was $84.6 \% \pm 0.1016$. From the preformulation studies, such high values were expected [22]. The mixture of the lipid (cetyl palmitate) with the PA decreased in crystallinity, making the nanoparticles more amorphous and offering room to accommodate more drug molecules, thus increasing the matrix capacity to load PA. The decreased crystallinity of lipid matrices, when loaded with monoterpenes, has also been reported by other authors [34, 37, 38].

The in vitro kinetics study was conducted to understand the release mechanism of PA from SLN (Supplementary material S1). Approximately $30 \%$ of the PA showed a modified release over the course of 8 hours without any burst effects with a prolonged kinetic profile over the course of the experiment. According to Oehlke et al. [16], the PA lipophilicity favors solubilization in the lipid matrix of the SLN, prolonging the release time. In a study by $\mathrm{Da}$ Rosa et al. [39], approximately $50 \%$ of loaded thymol and carvacrol took about 72 hours to be released from zein nanoparticles, demonstrating an extended release of monoterpenes. Zielinska et al. [9] also reported the modified release profile of several monoterpenes (i.e., alpha-pinene, citral, geraniol, and limonene) from glycerol monostearate composed SLN.

Mathematical modeling has been used to describe the release mechanism of PA from SLN, applying Baker and Lonsdale, Korsmeyer-Peppas, Hixon and Crowell, Higuchi, Square Root, First Order, and Weibull. For each fitting model, $\mathrm{R}^{2}$ value has been determined for both profiles (free PA and SLN-PA), and parameters corresponding to the obtained release data are shown in Table 1. Both release profiles could be better described by the Korsmeyer-Peppas fitting model as the $\mathrm{R}^{2}$ value was found to be a 
perfect linear correlation kinetics for PA before and after its loading into lipid nanoparticles. Korsmeyer-Peppas model is generally used to describe the release of a drug from a matrix when the mechanism is not well known or when one or more types of phenomena are involved [24]. This model is described by the power-law equation $M_{t} / M_{\infty}=k^{\prime} t^{n}$, in which $M_{t}$ translates the cumulative amount of drug being released at the time $t, M_{\infty}$ is the cumulative amount of drug released at infinite time, $k^{\prime}$ is a constant governed by the physicochemical properties of the matrix, and $n$ is the diffusional release exponent. It is this latter, i.e., $n$ value, that describes the release mechanism of the drug. When $n=0.5$, the release is governed by the Fickian diffusion, when $0.5<n<1.0$, a non-Fickian diffusion is observed. When the drug release becomes time-independent, it becomes a zero-order release in a Case II transport, as seen in spherical particles. When $n$ approaches 1.0, a typical release following a non-Fickian transport is observed. In the case of SLN, the type of solid lipid selected as matrix material plays a critical role in the release kinetics profile, as the lipid is responsible for the solubility and entrapment of the drug within the solid matrix of SLN [40]. Cetyl palmitate is known to recrystallize in a metastable polymorphic which controls the drug outlet from the SLN. However, SLN matrix erodes, its porosity increases so that the drug can be released [26].

Table 1. In vitro release coefficient obtained from the different mathematical fitting models for free PA and SLN-PA profiles (Release profile depicted in Supplementary Material, S1).

\begin{tabular}{lcc}
\hline Mathematical model & Free PA & SLN-PA \\
\hline Baker and Lonsdale & 0.8146 & 0.8776 \\
Korsmeyer-Peppas & 1.0000 & 1.0000 \\
Hixon and Crowell & 0.9998 & 0.9989 \\
Higuchi, Square Root & 0.8191 & 0.8895 \\
First Order & 0.9997 & 0.9976 \\
\hline PA = perillyl alcohol; SLN-PA = solid lipid nanoparticles incorporated with perillyl alcohol
\end{tabular}

PA = perillyl alcohol; SLN-PA = solid lipid nanoparticles incorporated with perillyl alcohol.

Thermal analysis is a tool used to analyze polymorphic transitions and changes in lipids' physical and chemical properties as a function of temperature. In particular, the DSC method is the most frequently used in the investigation of the physical state of dispersed particles, detecting melting and endothermic transformations, which are typical upon heating (or the absence of these endotherms under cooling). DSC gives important information about the entrapped drug within SLN [41, 42]. Fusion can be associated with the dissolution of the drug in a lipid matrix or with the fusion of the complex formed between lipid and drug [43, 44]. The main use of TG comprises the evaluation of the thermal stability of drugs and carriers through thermal-induced weight loss of a sample as a function of temperature.

The TG/DTG curves of the PA revealed a loss of mass $\left(\Delta \mathrm{m}_{1} 91.43 \%\right.$. $)$, with an onset at $126^{\circ} \mathrm{C}$ and its end at approximately $177^{\circ} \mathrm{C}$, attributed to the decomposition of the monoterpene. Supplementary S2 shows the TG/DTG curves for PA, SLN, and SLN-PA. TG/DTG curves of the SLN showed a mass loss event between 220.10 and $326.68^{\circ} \mathrm{C}\left(\Delta \mathrm{m}_{1} 91.43 \%\right)$, attributed to the degradation of the lipid. Similar mass loss events for the wax cetyl palmitate have been reported elsewhere $[22,45,46]$. The SLN-PA showed a mass loss event between 244.74 and $326.48{ }^{\circ} \mathrm{C}$ related to the loss of mass of $\Delta \mathrm{m}_{1} 34.5 \%$, following one thermal event attributed to the decomposition. The monoterpene loading into SLN changed the thermal properties of the lipid, indicating the presence of the drug within the SLN matrix.

The thermal analysis of SLN is instrumental in estimating the stability of the lipid matrix [47]. DSC profiles of the PA, SLN, and SLNPA are shown in Supplementary S3. The DSC curve of PA showed an endothermic event between 121.99 and $146.99^{\circ} \mathrm{C} \quad(\Delta H=$ $456.88 \mathrm{Jg}^{-1}$ ) attributed to the volatilization and decomposition of the monoterpene. The DSC profile curve of SLN exhibited one endothermic peak valued between 48.36 and $60.75^{\circ} \mathrm{C}$ $\left(\Delta H=-113.39 \mathrm{Jg}^{-1}\right)$, which corresponds to the melting of the solid lipid (cetyl palmitate), as confirmed by the literature $[22,45,46]$. The 
loading of PA into the SLN resulted in some modifications of the thermal behavior. The SLN-PA thermogram showed an endothermic peak with two maxima. The first one is visible between 46.22 and $54.32^{\circ} \mathrm{C}\left(\Delta H-26.37 \mathrm{Jg}^{-1}\right)$ and the second between 54.32 to $60.79^{\circ} \mathrm{C}$ $\left(\Delta H=-3.82 \mathrm{Jg}^{-1}\right)$. The endothermic peak was absent in the range of volatilization of PA, which can be explained considering the dissolution of PA in the molten lipid during encapsulation [37]. The formulation showed a melting peak higher than $45^{\circ} \mathrm{C}$. This characteristic ensures the solid structure of particles at room temperature $\left(\sim 25^{\circ} \mathrm{C}\right)$.

The morphology of SLN and SLN-PA was visualized by TEM (Supplementary S4). Figure S4A shows the spherical and smooth shape of PA-free SLN. The loading of PA into SLN also resulted in SLN of spherical shape and smooth surface (S4B), in which black points are visible with higher resolution, suggesting the effective encapsulation of PA into the lipid matrix. TEM results are in agreement with the recorded mean diameters by dynamic light scattering, also reported by other authors $[48,49]$.

The cytotoxicity profile of SLN (with and without PA) was evaluated against L929 murine fibroblast cells. As shown in Figure 1, all tested samples (i.e., control group, bulk PA, SLN, and SLN-PA) showed cellular viability of above $\quad 70 \%$, i.e., $\quad 99.57 \pm 0.30 \%$, $94.6 \pm 5.51 \%, 99.14 \pm 1.03 \%, 99.6 \pm 0.37 \%$, respectively. Free PA was also shown to be non-cytotoxic against normal fibroblasts; cell viability was greater than $99 \%$. Besides, isolated PA showed a similar result compared to SLN-PA, which also did not induce any toxic effect. The results indicate the safety and biocompatibility of formulations and free PA for eukaryotic cells. Any cytotoxic effect of nanoparticles in vitro results from their adhesion to the cell membrane, their internalization, and degradation inside the cells $[50,51]$. The cell susceptibility to a specific product is dependent on the type of cell [52], and is governed by the physicochemical properties of the surface and matrix of the particles. While enough evidence on their preclinical safety based on the biocompatibility and biodegradability of lipids has been gathered, the main critical issue is the type of surfactant surrounded by the particles on the cell viability in vitro [17]. SLN were obtained from cetyl palmitate surrounded by a non-ionic surfactant (Pluronic ${ }^{\mathbb{}}$ F68). Cetyl palmitate is a naturally occurring vegetable wax derived from cetyl alcohol and palmitic acid, with a hydrophilic-lipophilic balance value of 10 . Pluronic is a polyoxyethylene-polyoxypropylene block copolymer suitable for cell culture. Both substances are generally recognized as safe, while literature has demonstrated in vitro biocompatibility of such systems. Cytotoxic activity of PA against tumor cell lines of ovarian adenocarcinoma (OVCAR-8), colon carcinoma (HCT116), and glioblastoma (SF295) has already been shown by us [31]. The effect of the PA loading on the viability of L929 fibroblast cells was evaluated (Figure 1).

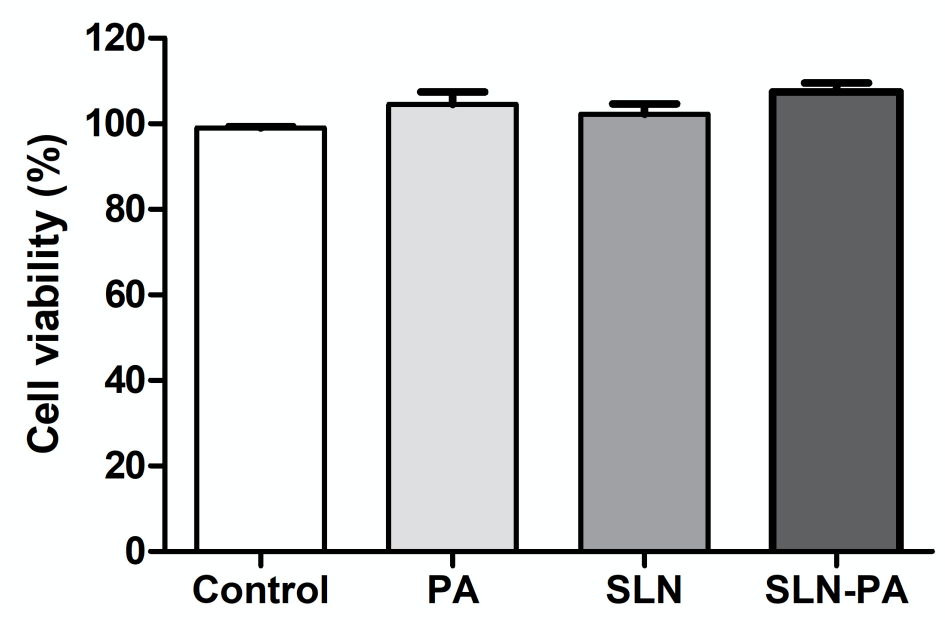

Figure 1. Effect of perillyl alcohol (PA), solid lipid nanoparticles (SLN), and solid lipid nanoparticles-perillyl alcohol (SLN-PA) on the viability of human L929 fibroblasts determined by MTT assay after 24 hours of incubation. The control group was treated with the vehicle used to dilute the drug (DMSO 5\%). The data correspond to the mean \pm standard error of the mean of four independent experiments. 
Cell viability remained above $99 \%$ for all tested samples in comparison to control, confirming the lack of cytotoxicity of PA, SLN, and SLN-PA on mouse L929 fibroblasts.

Figure 2 shows the values of the tumor inhibition rate and tumor mass of the treated animals and their respective controls. After intraperitoneal administration, SLN-PA inhibited tumor growth in $51.76 \%(0.95 \pm 0.07 \mathrm{~g})$ and $54.49 \%(0.90 \pm 0.08 \mathrm{~g})$ in doses of 100 and $200 \mathrm{mg} / \mathrm{kg} /$ day, respectively. 5-FU (positive control, PC) in the dose of $25 \mathrm{mg} / \mathrm{kg} /$ day inhibited tumor growth in $91.07 \%(0.14 \mathrm{~g} \pm 0.12 \mathrm{~g})$. These results show that the SLN-PA at doses of 100 and $200 \mathrm{mg} / \mathrm{kg} /$ day have Antitumor effect in the sarcoma 180 mice model.

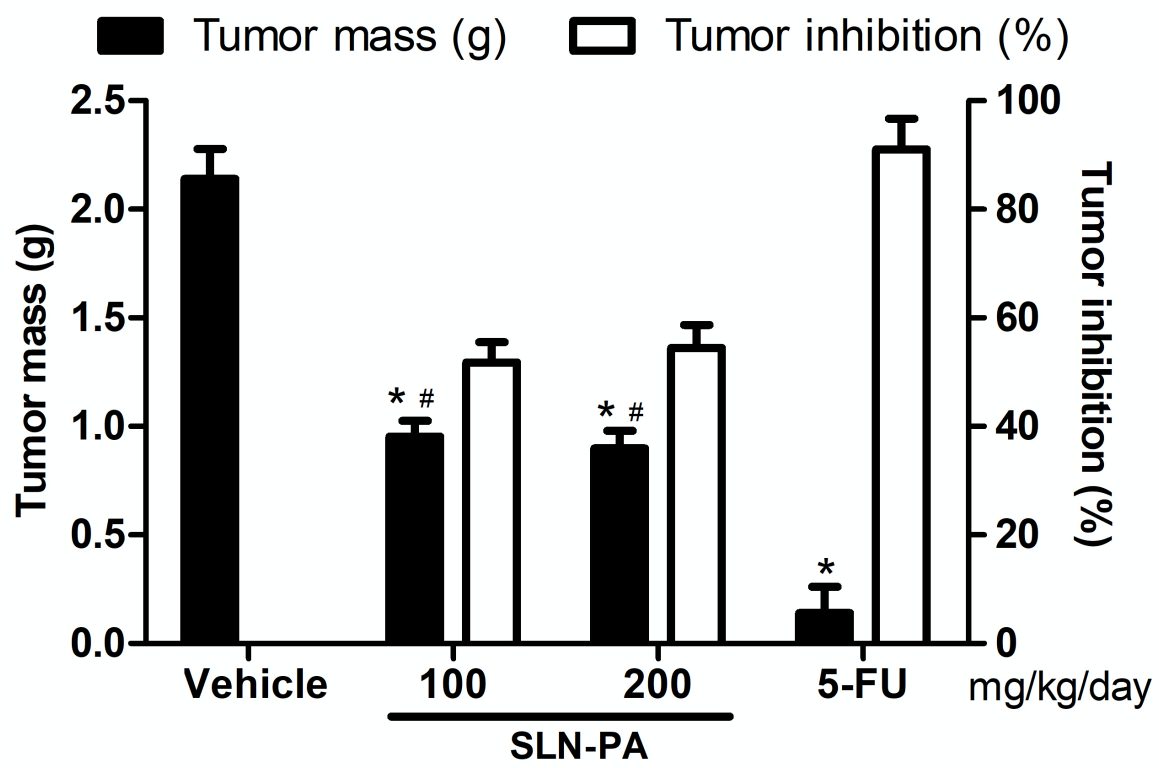

Figure 2. In vivo antitumor activity of solid lipid nanoparticles incorporated with perillyl alcohol (SLN-PA) in doses of 100 and $200 \mathrm{mg} / \mathrm{kg} /$ day (intraperitoneal) for seven consecutive days. The vehicle-treated group was treated with DMSO 5\% and positive control treated with 5-Fluorouracil (5-FU $25 \mathrm{mg} / \mathrm{kg} /$ day). Values correspond to the mean $\pm \sigma$ of 10 animals/group analyzed by ANOVA followed by Student Newman Keuls post-test. ${ }^{*} p<0.05$ compared to the negative control group.

Andrade et al. [28] evaluated the in vivo Antitumor effect of isolated PA (intraperitoneally) in the sarcoma 180 model, demonstrating tumor growth inhibition of $35.3 \%$ and $45.4 \%$ for the doses of 100 and $200 \mathrm{mg} / \mathrm{kg} / \mathrm{day}$, respectively. Comparing these latter with the results obtained in the present work, an increase in tumor growth inhibition was observed for SLN-PA when comparing both PA doses. SLN-PA increased the Antitumor effect of the drug against sarcoma 180 without the need to increase dosage. Other antineoplastics as camptothecin, doxorubicin, methotrexate, mitoxantrone, oxaliplatin, and tamoxifen are examples of chemotherapeutics that use SLN to prolong the release of the drug, increase the amount of drug in the bloodstream, facilitate the cellular uptake of the incorporated drugs by the modulation of passive, active, cotransport mechanisms and can overcome biological barriers which result in improving cytotoxic activity or inhibition rate of tumor growth in vivo [53].
Most antineoplastic drugs currently used are cytotoxic to tumor cells, but they also have nonspecific action as they reach healthy cells, leading to undesirable side effects. All antineoplastic drugs cause gastrointestinal changes and weight loss in a murine model [54]. The first parameter to be analyzed is, therefore, the variation in body mass. The results demonstrate that the groups of animals treated with SLN-PA in both doses show a reduction in body mass; however, less than the 5-FU antineoplastic (Table 2). Despite the different administration routes, these results corroborate with those obtained from human clinical trials, which demonstrated that patients using oral PA might experience nausea, vomiting, fatigue, lack of appetite, and consequently reduced body mass [55]. Based on these effects, oral PA did not advance to phase 3 clinical trials and, therefore, has not entered clinical practice for cancer treatment [11]. 
Table 2. Toxicological parameters of the evaluation of perillyl alcohol

\begin{tabular}{clccc}
\hline \multirow{2}{*}{ Parameters } & \multicolumn{3}{c}{ Treatments (mg/kg/day) } \\
\cline { 2 - 5 } & \multicolumn{1}{c}{ Vehicle } & \multicolumn{2}{c}{ SLN-PA } & 5-FU \\
\cline { 2 - 5 } & \multicolumn{1}{c}{-} & \multicolumn{1}{c}{100} & 200 & 25 \\
\hline Body weight $(\mathrm{g})$ & $1.10 \pm 0.27$ & $-0.88 \pm 0.34+$ & $-0.73 \pm 0.29^{*}$ & $-2.40 \pm 0.34^{*}$ \\
\hline Liver (g/100g body weight) & $4.86 \pm 0.08$ & $4.99 \pm 0.19$ & $4.90 \pm 0.22$ & $4.63 \pm 0.12$ \\
\hline Spleen (g/100g body weight) & $0.49 \pm 0.02$ & $0.44 \pm 0.04$ & $0.47 \pm 0.08$ & $0.36 \pm 0.04^{*}$ \\
\hline Kidney (g/100g body weight) & $1.09 \pm 0.08$ & $1.10 \pm 0.04$ & $1.11 \pm 0.1$ & $1.11 \pm 0.06$ \\
\hline AST (U/L) & $268 \pm 22.5$ & $293.3 \pm 20.9$ & $294.1 \pm 16.2$ & $186.1 \pm 18.3$ \\
\hline ALT (U/L) & $56.4 \pm 3.8$ & $70.8 \pm 7.6$ & $66.4 \pm 3.9$ & $61.5 \pm 4.7$ \\
\hline Urea (mg/dL) & $41.6 \pm 4.5$ & $42.3 \pm 2.2$ & $36.1 \pm 2.2$ & $35 \pm 4.6$ \\
\hline Creatinine (mg/dL) & $1.7 \pm 0.1$ & $1.4 \pm 0.1$ & $1.4 \pm 0.1$ & $1.8 \pm 0.1$ \\
\hline Total leukocytes $\left(\times 10^{3}\right.$ cells/ $\left.\mu \mathrm{L}\right)$ & $9.9 \pm 0.7$ & $7.5 \pm 0.3^{* *}$ & $6.8 \pm 0.5^{*}$ & $2.2 \pm 0.6^{*}$ \\
\hline Neutrophil $(\%)$ & $39.6 \pm 3.5$ & $23.3 \pm 3.0^{*}$ & $22.9 \pm 1.6^{*}$ & $12.4 \pm 2.5^{*}$ \\
\hline Lymphocyte $(\%)$ & $56 \pm 3.8$ & $73 \pm 2.7^{*}$ & $74 \pm 1.2^{*}$ & $88.6 \pm 2.2^{*}$ \\
\hline Monocyte $(\%)$ & $1.5 \pm 0.2$ & $1.8 \pm 0.4$ & $1.7 \pm 0.3$ & $0.5 \pm 0.3$
\end{tabular}

AST $=$ aspartate aminotransferase $;$ ALT $=$ alanine aminotransferase; SLN-PA $=$ solid lipid nanoparticles incorporated with perillyl alcohol. Data are presented as mean values \pm standard error of mean of 8 mice by group with sarcoma 180. 5-FU: 5-Fluorouracil used as the positive control intraperitoneally. ${ }^{*} p<0.05$ when compared with the vehicle and ${ }^{\#} \mathrm{p}<0.05$ when compared with 5-FU using one-way ANOVA and Tukey test for multiple comparisons.

As renal and liver disorders are common outcomes of chemotherapy, their functions were investigated by determining organ mass, biochemical parameters (hepatic - AST and ALT, renal - urea and creatinine), and histopathological section (Table 3, Figure 2 and 3) of animals treated with SLN-PA. None of these parameters showed significant changes, indicating the formulation does not promote liver and kidney damage when used for 7 consecutive days on front sarcoma 180. These results corroborate with data obtained with derivatives of PA (perillaldehyde 8,9-epoxide and perillaldehyde 1,2-epoxide) in animals with sarcoma 180 , treated for 7 consecutive days intraperitoneally, where liver or kidney changes are not observed either [28, 31].

The immunological parameters evaluated in animals treated with SLN-PA were spleen mass, total leukocytes count, and differential count. Antineoplastic agents commonly cause changes in the immune system with variation in the mass of lymphoid organs (spleen), leukopenia, and changes in the ratio of lymphocytes and neutrophils in the differential count [56].
In the animals treated with this formulation, a reduction in spleen mass, a reduction in the number of total leukocytes (leukopenia), and a significant change in the amounts of circulating lymphocytes and neutrophils was observed. These results suggest that the SLN-PA can cause immunosuppression. Upon microscopic examination, the livers of animals treated with SLN-PA $100 \mathrm{mg} / \mathrm{kg}$ and $200 \mathrm{mg} / \mathrm{kg}$ did not show any morphological changes (Figure 3A).

The lobular-type architecture was observed, with thin-walled, equidistant terminal hepatic veins, portal spaces, regularly distributed and small, with a lax matrix comprising biliary vascular tracts (bile ducts, portal vein branch, and branches of the hepatic artery without histological particularities). In the portal spaces, normal hepatocytes were observed. Kidneys removed from the group treated with SLN-PA at doses of 100 and $200 \mathrm{mg} / \mathrm{kg}$ showed normal morphological standards (Figure 3B).

Namely, the lobes were well defined and with medullary rays, represented by the medullary pyramid and cortical tissue covering their base and sides. 

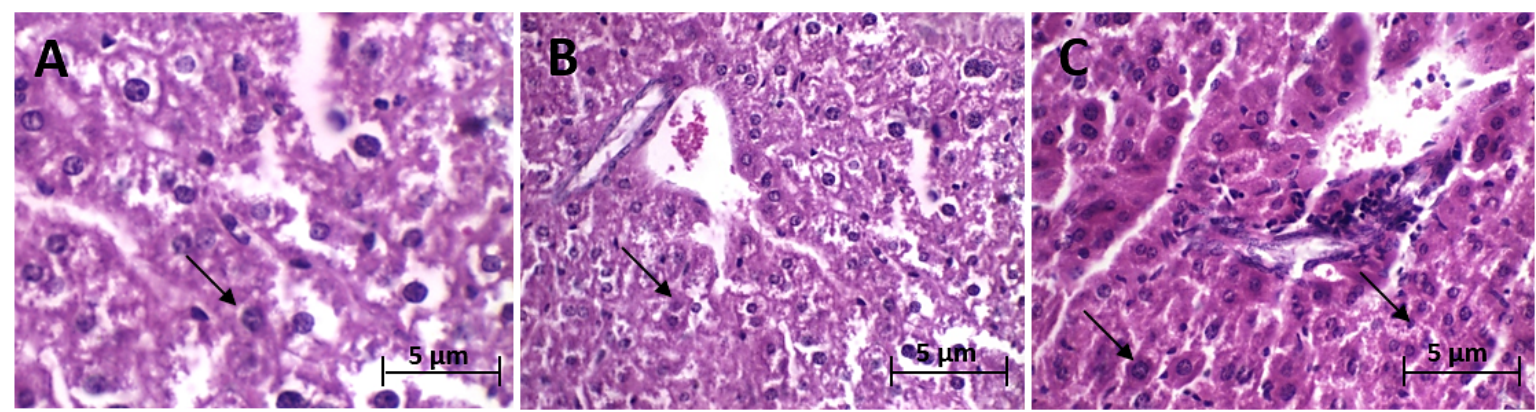

(a)
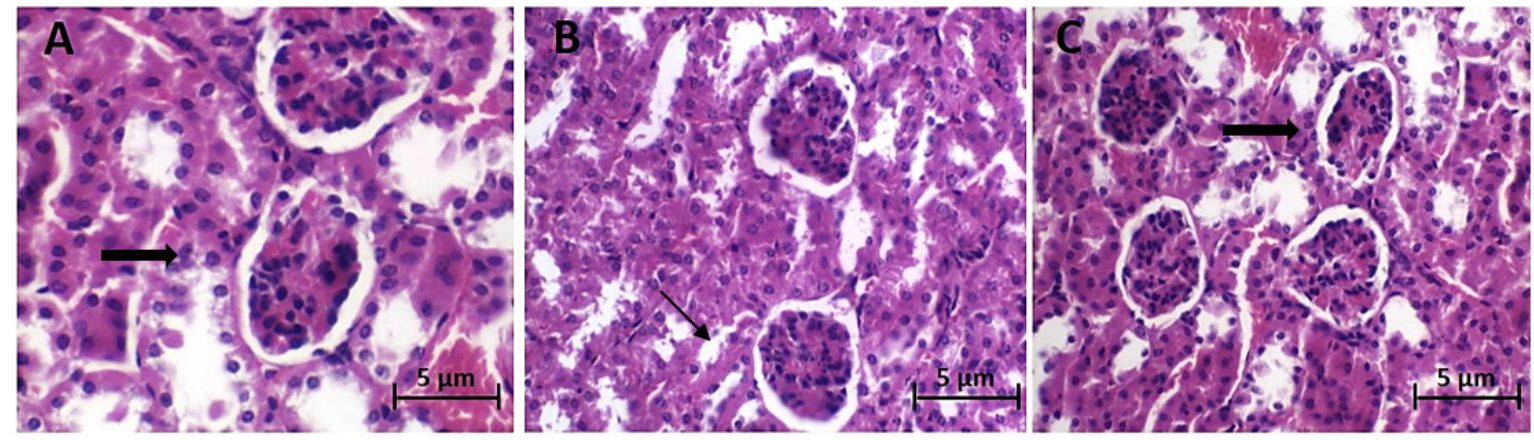

(b)

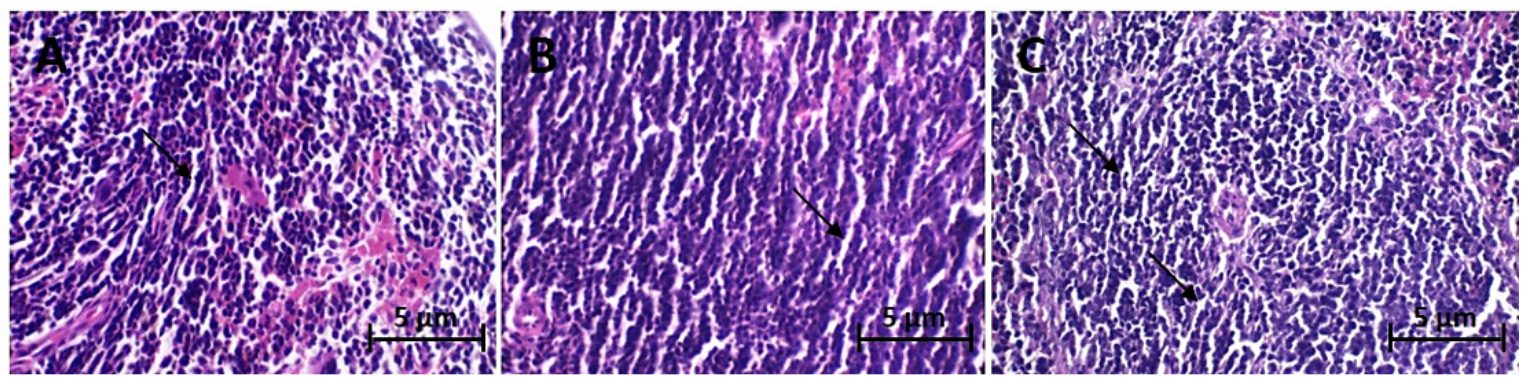

(c)

Figure 3. Histopathology of the experimental groups: (A, left panels) healthy tissue, (B, middle panels) and (C, right panels) of solid lipid nanoparticles incorporated with perillyl alcohol (SLN-PA) $100 \mathrm{mg} / \mathrm{kg}$ and $200 \mathrm{mg} / \mathrm{kg}$, respectively. The tissue sections were stained with hematoxylin and eosin $(H \& E)$ and analyzed by optical microscopy $(\times 400)$, at $5 \mu$ m thickness. (a) Photomicrograph of the liver. The black arrows indicate normal hepatocytes and Kupffer cells. (b) Photomicrograph of the kidney. The black arrows indicate the Bowman space (thin arrows) and preserved proximal contorted tubules (thick arrows) common in all groups. (c) Photomicrograph of the spleen. The black arrows indicate the splenic trabeculae and normal splenic sinuses.

The analysis performed by optical microscopy showed conserved and well-distributed cortical and medullary regions. The glomeruli belonging to the animals of the transplanted control group SLN-PA (100 and 200 $\mathrm{mg} / \mathrm{kg}$ /day) were surrounded by a thin Bowman capsule, the Bowman space, and capillary tuft being sustained for delicate melange.

The contorted proximal tubules, collecting tubules, and Henle loops were supported by scarce fibroconjunctive tissue and covered by epithelium with variable height, from columnar to pavement, typical of renal tissue. The medul-

lary region also showed collecting tubules directed towards the papillae, outlined by tall cells, with clearly visible cytoplasm.

The same was observed in the spleen microscopy without histopathological changes. Solid, lobulated configuration, with thin septa of fibrocollagenic tissues scarce intratumoral stroma, a proliferation of immature cells, small or medium-sized, irregularly shaped, some of which are bizarre, multinucleated and giant. They exhibit eosinophilic cytoplasms, with clear borders, hyperchromatic or vesicular nuclei with coarse chromatin, oval or pleomorphic, with prominent nucleoli (Figure 3C). 


\section{Conclusions}

Solid lipid nanoparticles have been used to improve the effectiveness of volatile and lipophilic active ingredients by increasing the pharmacological activity at the site of action, the half-life, as well as minimizing systemic variability. The loading of PA in the SLN improved the safety profile of the drug and prolonged its release. SLN containing PA demonstrated an antitumor effect in vivo in a sarcoma 180 tumor model with few changes in toxicological parameters, which demonstrates the potential applicability of SLN-PA for cancer therapy. Due to the versatility of SLN, these are promising nanocarriers for chemotherapy as they show high bioavailability, low toxicity, effective transport between physiological barriers, thus determining the supply of drugs to target cells. SLN represents a promising system for the incorporation of active ingredients with antitumor effects, such as PA.

\section{Acknowledgments}

This work was supported by the Banco do Nordeste (grant FUNDECI/2016.0015), Conselho Nacional de Desenvolvimento Científico e Tecnológico (CNPq), Fundação de Apoio à Pesquisa e à Inovação Tecnológica do Estado de Sergipe (Fapitec) and Coordenação de Aperfeiçoamento de Pessoal de Nível Superior (CAPES). Eliana B. Souto would like to acknowledge the Portuguese Science and Technology Foundation (FCT/MCT) and from European Funds (PRODER/COMPETE) for the project UIDB/04469/2020 (strategic fund), co-financed by FEDER, under the Partnership Agreement PT2020.

\section{Conflict of interests}

The authors report no conflict of interest. For a signed statement, please contact the journal office: editor@precisionnanomedicine.com

Quote this article as Andrade LN, Cavendish MSS, Costa SPM, Amaral RG, Corrêa CB, Oliveira DS, Morsink M, Gokce EH, de Albuquerque Jr. RLC, Souto EB, Severino P, Perillyl Alcohol in Solid Lipid Nanoparticles (SLN-PA): Cytotoxicity and Antitumor Potential in Sarcoma 180 Mice Model, Precis. Nanomed. 2020;3(4):685-698, https://doi.org/10.33218/001c.17880

\section{References}

[1] C.-Y. Zhao, R. Cheng, Z. Yang, Z.-M. Tian, Nanotechnology for cancer therapy based on chemotherapy, Molecules, 23 (2018) 826.

[2] H. Hu, Q. Zhu, X.S. Luo, X.W. Yang, H.D. Wang, C.Y. Guo, Efficacy of PD-1/PD-L1 inhibitors against pretreated advanced cancer: a systematic review and meta-analysis, Oncotarget, 9 (2018) 11846.

[3] P. Fox, A. Darley, E. Furlong, C. Miaskowski, E. Patiraki, J. Armes, E. Ream, C. Papadopoulou, L. McCann, N. Kearney, The assessment and management of chemotherapy-related toxicities in patients with breast cancer, colorectal cancer, and Hodgkin's and non-Hodgkin's lymphomas: A scoping review, European Journal of Oncology Nursing, 26 (2017) 63-82.

[4] K. Krukiewicz, J.K. Zak, Biomaterial-based regional chemotherapy: Local anticancer drug delivery to enhance chemotherapy and minimize its side-effects, Materials Science and Engineering: C, 62 (2016) 927-942.

[5] S. Antoni, I. Soerjomataram, B. Møller, F. Bray, J. Ferlay, An assessment of GLOBOCAN methods for deriving national estimates of cancer incidence, Bulletin of the World Health Organization, 94 (2016) 174.

[6] J. Ferlay, I. Soerjomataram, R. Dikshit, S. Eser, C. Mathers, M. Rebelo, D.M. Parkin, D. Forman, F. Bray, Cancer incidence and mortality worldwide: sources, methods and major patterns in GLOBOCAN 2012, International Journal of Cancer, 136 (2015) E359-E386.

[7] I. Pereira, A. Zielinska, N.R. Ferreira, A.M. Silva, E.B. Souto, Optimization of linalool-loaded solid lipid nanoparticles using experimental factorial design and long-term stability studies with a new centrifugal sedimentation method, International Journal of Pharmaceutics, 549 (2018) 261-270.

[8] A. Zielinska, N.R. Ferreira, A. Durazzo, M. Lucarini, N. Cicero, S.E. Mamouni, A.M. Silva, I. Nowak, A. Santini, E.B. Souto, Development and Optimization of Alpha-Pinene-Loaded Solid Lipid Nanoparticles (SLN) Using Experimental Factorial Design and Dispersion Analysis, Molecules, 24 (2019). 
[9] A. Zielińska, N.R. Ferreira, A. Feliczak-Guzik, I. Nowak, S. EB, Loading, release profile and accelerated stability assessment of monoterpenes-loaded Solid Lipid Nanoparticles (SLN), Pharmaceutical Development and Technology, 25 (2020) 832-844.

[10] A. Zielinska, C. Martins-Gomes, N.R. Ferreira, A.M. Silva, I. Nowak, E.B. Souto, Anti-inflammatory and anticancer activity of citral: Optimization of citral-loaded solid lipid nanoparticles (SLN) using experimental factorial design and LUMiSizer(R), International Journal of Pharmaceutics, 553 (2018) 428-440.

[11] T.C. Chen, C.O. Da Fonseca, A.H. Schönthal, Perillyl alcohol and its drug-conjugated derivatives as potential novel methods of treating brain metastases, International journal of molecular sciences, 17 (2016) 1463.

[12] M.A. Ansari, Z. Fatima, S. Hameed, Anticandidal effect and mechanisms of monoterpenoid, perillyl alcohol against Candida albicans, PloS one, 11 (2016).

[13] CO Da Fonseca, H. Khandelia, M.D.A. Salazar, A.H. Schönthal, O.C. Meireles, T. Quirico-Santos, Perillyl alcohol: Dynamic interactions with the lipid bilayer and implications for long-term inhalational chemotherapy for gliomas, Surgical neurology international, 7 (2016).

[14] A. Marchese, C.R. Arciola, R. Barbieri, A.S. Silva, S.F. Nabavi, T. Sokeng, A. Jorel, M. Izadi, N.J. Jafari, I. Suntar, Update on monoterpenes as antimicrobial agents: A particular focus on p-cymene, Materials, 10 (2017) 947.

[15] N. Naseri, H. Valizadeh, P. Zakeri-Milani, Solid lipid nanoparticles and nanostructured lipid carriers: structure, preparation and application, Advanced pharmaceutical bulletin, 5 (2015) 305.

[16] K. Oehlke, D. Behsnilian, E. Mayer-Miebach, P.G. Weidler, R. Greiner, Edible solid lipid nanoparticles (SLN) as carrier system for antioxidants of different lipophilicity, PloS one, 12 (2017).

[17] S. Doktorovova, A.B. Kovacevic, M.L. Garcia, E.B. Souto, Preclinical safety of solid lipid nanoparticles and nanostructured lipid carriers: Current evidence from in vitro and in vivo evaluation, European Journal of Pharmaceutics and Biopharmaceutics, 108 (2016) 235-252.

[18] S. Doktorovova, A.M. Silva, I. Gaivao, E.B. Souto, J.P. Teixeira, P. Martins-Lopes, Comet assay reveals no genotoxicity risk of cationic solid lipid nanoparticles, Journal of Applied Toxicology, 34 (2014) 395-403.

[19] S. Doktorovova, E.B. Souto, A.M. Silva, Nanotoxicology applied to solid lipid nanoparticles and nanostructured lipid carriers - a systematic review of in vitro data, Eur J Pharm Biopharm, 87 (2014) 118.

[20] S. Jose, S.S. Anju, T.A. Cinu, N.A. Aleykutty, S. Thomas, E.B. Souto, In vivo pharmacokinetics and biodistribution of resveratrol-loaded solid lipid nanoparticles for brain delivery, International Journal of Pharmaceutics, 474 (2014) 6-13.

[21] E.B. Souto, S. Doktorovova, J.R. Campos, P. Martins-Lopes, A.M. Silva, Surface-tailored antiHER2/neu-solid lipid nanoparticles for site-specific targeting MCF-7 and BT-474 breast cancer cells, European Journal of Pharmaceutical Science, 128 (2019) 27-35.

[22] M. Cavendish, L. Nalone, T. Barbosa, R. Barbosa, S. Costa, R. Nunes, C.F. da Silva, M.V. Chaud, E.B. Souto, L. Hollanda, P. Severino, Study of pre-formulation and development of solid lipid nanoparticles containing perillyl alcohol, Journal of Thermal Analysis Calorimetry, (2019) 1-8.

[23] E.B. Souto, A. Zielinska, S.B. Souto, A. Durazzo, M. Lucarini, A. Santini, A.M. Silva, A.G. Atanasov, C. Marques, L.N. Andrade, P. Severino, (+)-Limonene 1,2-epoxide-loaded SLN: evaluation of drug release, antioxidant activity and cytotoxicity in HaCaT cell line, International Journal of Molecular Sciences, 21 (2020) E1449.

[24] E.B. Souto, S.B. Souto, A. Zielinska, A. Durazzo, M. Lucarini, A. Santini, O.K. Horbańczuk, A.G. Atanasov, C. Marques, L.N. Andrade, A.M. Silva, P. Severino, Perillaldehyde 1,2-epoxide loaded SLN-tailored $\mathrm{mAb}$ : Production, physicochemical characterization and in vitro cytotoxicity profile in MCF-7 cell lines, Pharmaceutics, 12 (2020) 161.

[25] E.B. Souto, A.J. Almeida, R.H. Müller, Lipid Nanoparticles (SLN®, NLC $\left.{ }^{2}\right)$ for Cutaneous Drug Delivery:Structure, Protection and Skin Effects, Journal of Biomedical Nanotechnology, 3 (2007) 317331. 
[26] L.N. Andrade, D.M.L. Oliveira, M.V. Chaud, T.F.R. Alves, M. Nery, C.F. da Silva, J.K.C. Gonsalves, R.S. Nunes, C.B. Corrêa, R.G. Amaral, E. Sanchez-Lopez, E.B. Souto, P. Severino, Praziquantel-Solid Lipid Nanoparticles Produced by Supercritical Carbon Dioxide Extraction: Physicochemical Characterization, Release Profile, and Cytotoxicity, Molecules (Basel, Switzerland), 24 (2019) 3881.

[27] H. Schepers, R. Brasseur, E. Goormaghtigh, P. Duquenoy, J.M. Ruysschaert, Mode of insertion of praziquantel and derivatives into lipid membranes, Biochemical pharmacology, 37 (1988) 16151623.

[28] L.N. Andrade, R.G. Amaral, G.A.A. Dória, C.S. Fonseca, T.K.M. Da Silva, R.L.C. Albuquerque Júnior, S.M. Thomazzi, L.G. Do Nascimento, A.A. Carvalho, D.P. De Sousa, In vivo antitumor activity and toxicological evaluations of Perillaldehyde 8, 9-Epoxide, a derivative of Perillyl alcohol, International journal of molecular sciences, 17 (2016) 32.

[29] D.P. Bezerra, F.O. Castro, A.P.N.N. Alves, C. Pessoa, M.O. Moraes, E.R. Silveira, M.A.S. Lima, F.J.M. Elmiro, L.V. Costa-Lotufo, In vivo growth-inhibition of Sarcoma 180 by piplartine and piperine, two alkaloid amides from Piper, Brazilian Journal of Medical Biological Research, 39 (2006) 801-807

[30] L.N. Andrade, P. Severino, R.G. Amaral, G. Anne, A. Dória, A. da Silva, M. Alves, R.L.C. Albuquerque, D.P. de Sousa, Evaluation of cytotoxic and antitumor activity of perillaldehyde 1, 2epoxide, (2018).

[31] L.N. Andrade, T.C. Lima, R.G. Amaral, O. Pessoa Cdo, MO Filho, BM. Soares, L.G. Nascimento, A.A. Carvalho, D.P. de Sousa, Evaluation of the cytotoxicity of structurally correlated p-menthane derivatives, Molecules, 20 (2015) 13264-13280.

[32] S. Doktorovova, E.B. Souto, A.M. Silva, Hansen solubility parameters (HSP) for prescreening formulation of solid lipid nanoparticles (SLN): in vitro testing of curcumin-loaded SLN in MCF-7 and BT-474 cell lines, Pharmaceutical Development and Technology, 23 (2018) 96-105.

[33] R.K. Jain, T. Stylianopoulos, Delivering nanomedicine to solid tumors, Nature Reviews Clinical Oncology, 7 (2010) 653-664.

[34] A. Khare, I. Singh, P. Pawar, K. Grover, Design and Evaluation of Voriconazole Loaded Solid Lipid Nanoparticles for Ophthalmic Application, Journal of drug delivery, 2016 (2016) 6590361.

[35] M.C. Smith, R.M. Crist, J.D. Clogston, S.E. McNeil, Zeta potential: a case study of cationic, anionic, and neutral liposomes, Analytical Bioanalytical Chemistry, 409 (2017) 5779-5787.

[36] S. Scioli Montoto, M.L. Sbaraglini, A. Talevi, M. Couyoupetrou, M. Di Ianni, G.O. Pesce, V.A. Alvarez, L.E. Bruno-Blanch, G.R. Castro, M.E. Ruiz, G.A. Islan, Carbamazepine-loaded solid lipid nanoparticles and nanostructured lipid carriers: Physicochemical characterization and in vitro/in vivo evaluation, Colloids and Surfaces B: Biointerfaces, 167 (2018) 73-81.

[37] B. Rodenak-Kladniew, G.A. Islan, MG de Bravo, N. Durán, G.R. Castro, Design, characterization and in vitro evaluation of linalool-loaded solid lipid nanoparticles as potent tool in cancer therapy, Colloids and Surfaces B: Biointerfaces, 154 (2017) 123-132.

[38] J.-S.B. Baek, 2018 \#8; Binnemars-Postma, 2017 \#9; Britto, 2012 \#10\}, Y.-G. Na, C.-W. Cho, Sustained cytotoxicity of wogonin on breast cancer cells by encapsulation in solid lipid nanoparticles, Nanomaterials, 8 (2018) 159.

[39] CG da Rosa, M.V. de Oliveira Brisola Maciel, S.M. de Carvalho, A.P.Z. de Melo, B. Jummes, T. da Silva, S.M. Martelli, M.A. Villetti, F.C. Bertoldi, P.L.M. Barreto, Characterization and evaluation of physicochemical and antimicrobial properties of zein nanoparticles loaded with phenolics monoterpenes, Colloids and Surfaces A: Physicochemical and Engineering Aspects, 481 (2015) 337-344.

[40] R. Vieira, P. Severino, L.A. Nalone, S.B. Souto, A.M. Silva, M. Lucarini, A. Durazzo, A. Santini, E.B. Souto, Sucupira Oil-Loaded Nanostructured Lipid Carriers (NLC): Lipid Screening, Factorial Design, Release Profile, and Cytotoxicity, Molecules, 25 (2020) 685.

[41] P. Severino, S.C. Pinho, E.B. Souto, M.H. Santana, Polymorphism, crystallinity and hydrophiliclipophilic balance of stearic acid and stearic acid-capric/caprylic triglyceride matrices for production of stable nanoparticles, Colloids Surf B Biointerfaces, 86 (2011) 125-130.

[42] E.B. Souto, W. Mehnert, R.H. Muller, Polymorphic behaviour of Compritol888 ATO as bulk lipid and as SLN and NLC, Journal of Microencapsulation, 23 (2006) 417-433. 
[43] H. Bunjes, T. Unruh, Characterization of lipid nanoparticles by differential scanning calorimetry, X-ray and neutron scattering, Advanced Drug Delivery Reviews, 59 (2007) 379-402.

[44] C. Domingo, J. Saurina, An overview of the analytical characterization of nanostructured drug delivery systems: Towards green and sustainable pharmaceuticals: A review, Analytica Chimica Acta, $744(2012) 8-22$.

[45] R.P. Tofani, Y.C. Sumirtapura, S.T. Darijanto, Formulation, characterisation, and in vitro skin diffusion of nanostructured lipid carriers for deoxyarbutin compared to a nanoemulsion and conventional cream, Scientia pharmaceutica, 84 (2016) 634-645.

[46] SS Montoto, M.L. Sbaraglini, A. Talevi, M. Couyoupetrou, M. Di Ianni, G.O. Pesce, V.A. Alvarez, L.E. Bruno-Blanch, G.R. Castro, M.E. Ruiz, Carbamazepine-loaded solid lipid nanoparticles and nanostructured lipid carriers: physicochemical characterization and in vitro/in vivo evaluation, Colloids and Surfaces B: Biointerfaces, 167 (2018) 73-81.

[47] O.N. Ciftci, F. Temelli, Formation of solid lipid microparticles from fully hydrogenated canola oil using supercritical carbon dioxide, Journal of Food Engineering, 178 (2016) 137-144.

[48] A. Polchi, A. Magini, J. Mazuryk, B. Tancini, J. Gapiński, A. Patkowski, S. Giovagnoli, C. Emiliani, Rapamycin loaded solid lipid nanoparticles as a new tool to deliver mTOR inhibitors: formulation and in vitro characterization, Nanomaterials, 6 (2016) 87.

[49] M. Rehman, A. Ihsan, A. Madni, SZ. Bajwa, D. Shi, T.J. Webster, W.S. Khan, Solid lipid nanoparticles for thermoresponsive targeting: evidence from spectrophotometry, electrochemical, and cytotoxicity studies, International journal of nanomedicine, 12 (2017) 8325.

[50] A.M. Silva, H.L. Alvarado, G. Abrego, C. Martins-Gomes, M.L. Garduno-Ramirez, M.L. Garcia, A.C. Calpena, E.B. Souto, In Vitro Cytotoxicity of Oleanolic/Ursolic Acids-Loaded in PLGA Nanoparticles in Different Cell Lines, Pharmaceutics, 11 (2019) 362.

[51] A.M. Silva, C. Martins-Gomes, T.E. Coutinho, J.F. Fangueiro, E. Sanchez-Lopez, T.N. Pashirova, T. Andreani, E.B. Souto, Soft Cationic Nanoparticles for Drug Delivery: Production and Cytotoxicity of Solid Lipid Nanoparticles (SLNs), Applied Sciences, 9 (2019) 4438.

[52] E.B. Souto, J.R. Campos, R. Da Ana, C. Martins-Gomes, A.M. Silva, S.B. Souto, M. Lucarini, A. Durazzo, A. Santini, Ocular Cell Lines and Genotoxicity Assessment, International Journal of Environmental Research and Public Health, 17 (2020).

[53] S. Mukherjee, S. Ray, R.S. Thakur, Solid lipid nanoparticles: a modern formulation approach in drug delivery system, I Indian Journal of Pharmaceutical Sciences, 71 (2009) 349-358.

[54] J.E. Talmadge, R.K. Singh, I.J. Fidler, A. Raz, Murine models to evaluate novel and conventional therapeutic strategies for cancer, The American journal of pathology, 170 (2007) 793-804.

[55] J.T. Belanger, Perillyl alcohol: applications in oncology, Alternative medicine review: a journal of clinical therapeutic, 3 (1998) 448-457.

[56] A.C. Britto, A.C. de Oliveira, R.M. Henriques, G.M. Cardoso, D.S. Bomfim, A.A. Carvalho, M.O. Moraes, C. Pessoa, M.L. Pinheiro, E.V. Costa, In vitro and in vivo antitumor effects of the essential oil from the leaves of Guatteria friesiana, Planta medica, 78 (2012) 409-414. 


\section{Supplementary material}

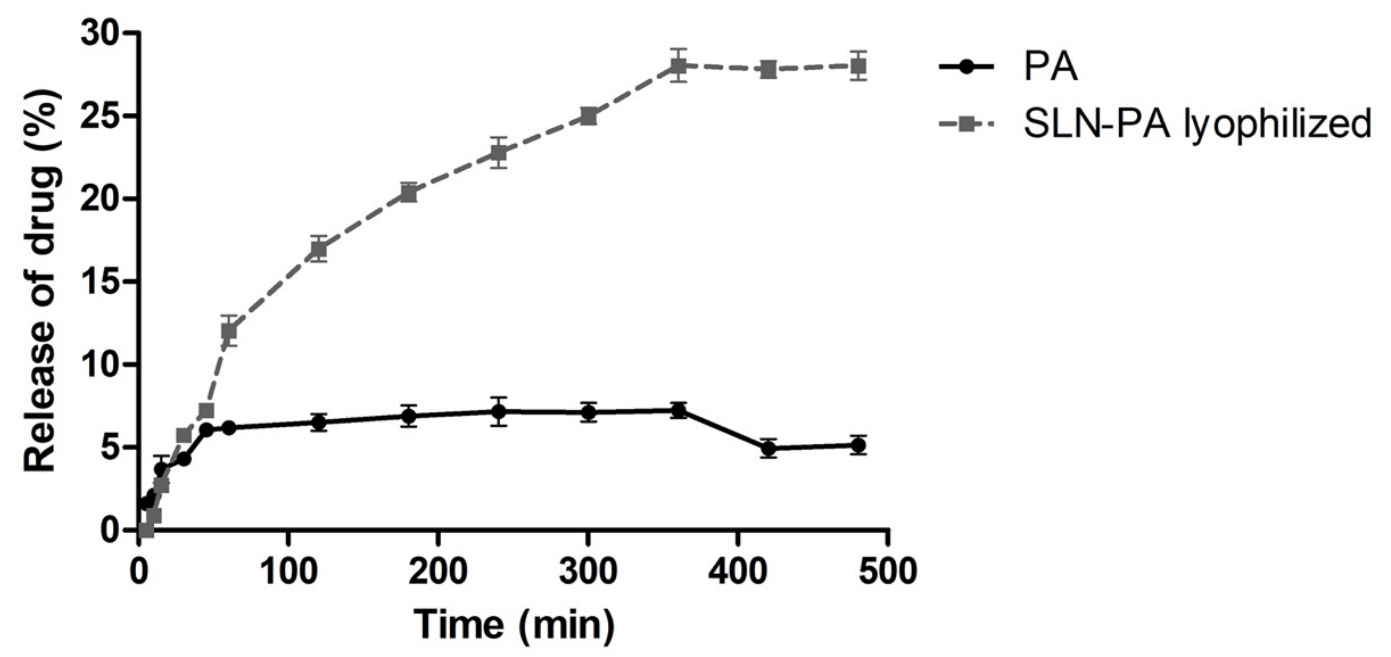

Figure S1. In vitro release profile of free PA and SLN-PA.

$P A=$ perillyl alcohol; $S L N-P A=$ solid lipid nanoparticles incorporated with perillyl alcohol

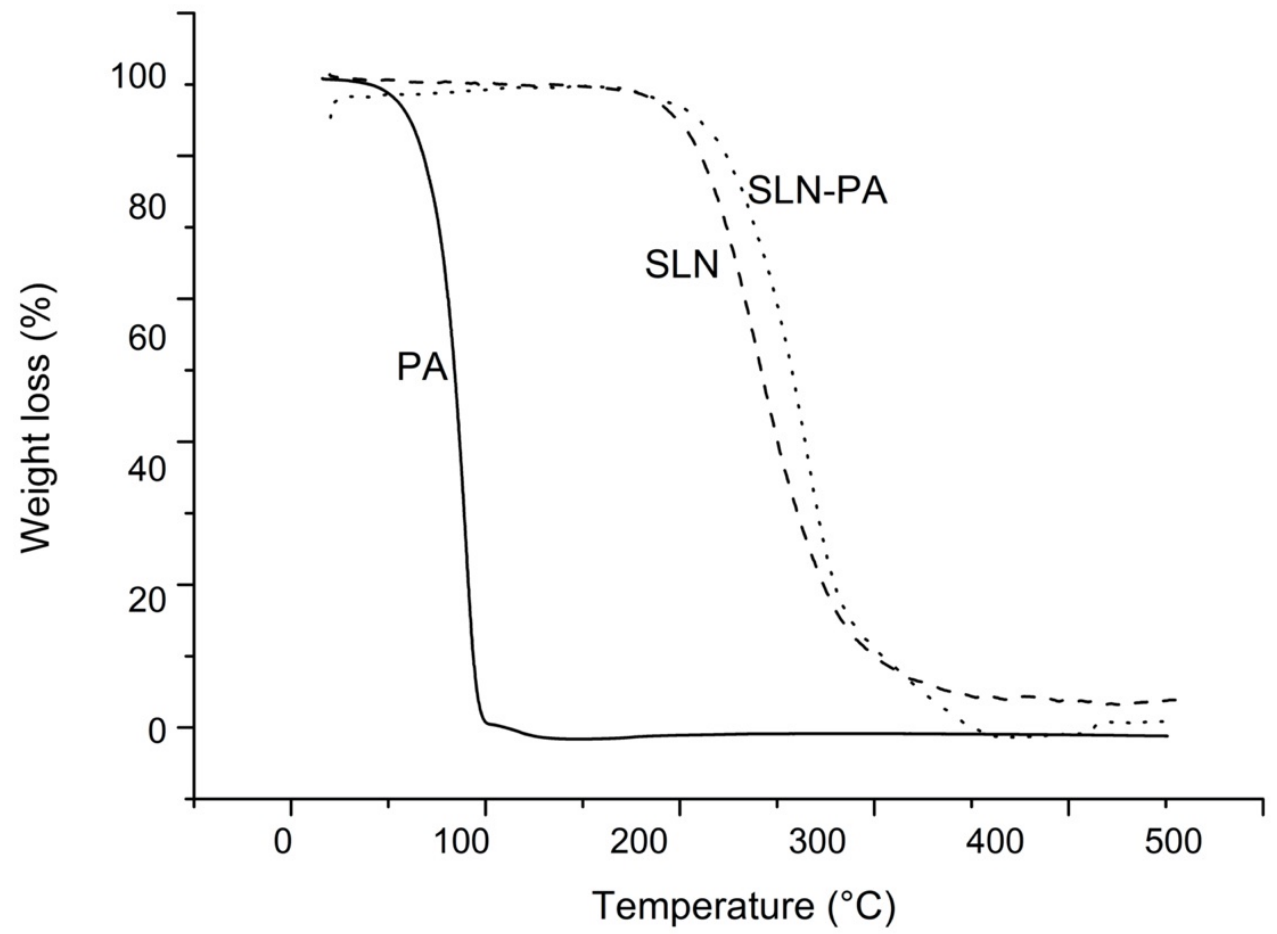

Figure $S 2 . T G / D T G$ curves of $P A, S L N$ and $S L N-P A . T G / D T G=$ thermogravimetry/derivative thermogravimetry; $P A=$ perillyl alcohol; $S L N=$ solid lipid nanoparticles; $S L N-P A=$ solid lipid nanoparticles incorporated with perillyl alcohol. 


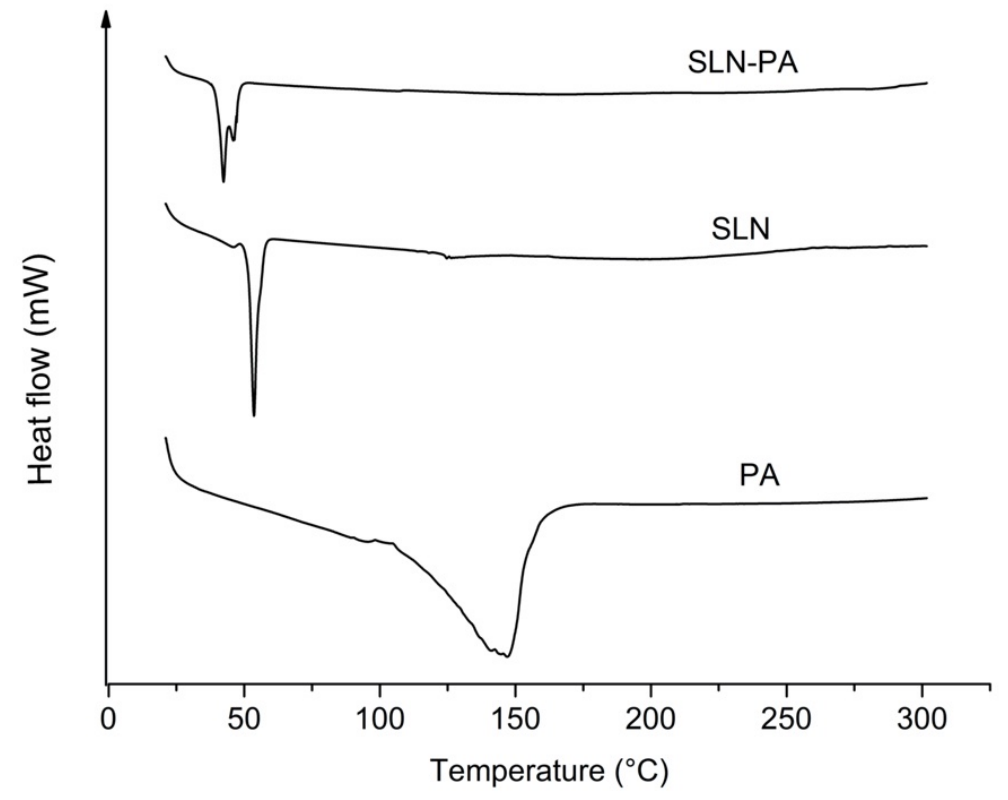

Figure S3. DSC curves of PA, SLN and SLN-PA.

$D S C=$ differential scanning calorimetry; $P A=$ perillyl alcohol; $S L N=$ solid lipid nanoparticles; $S L N-P A=$ solid lipid nanoparticles incorporated with perillyl alcohol.

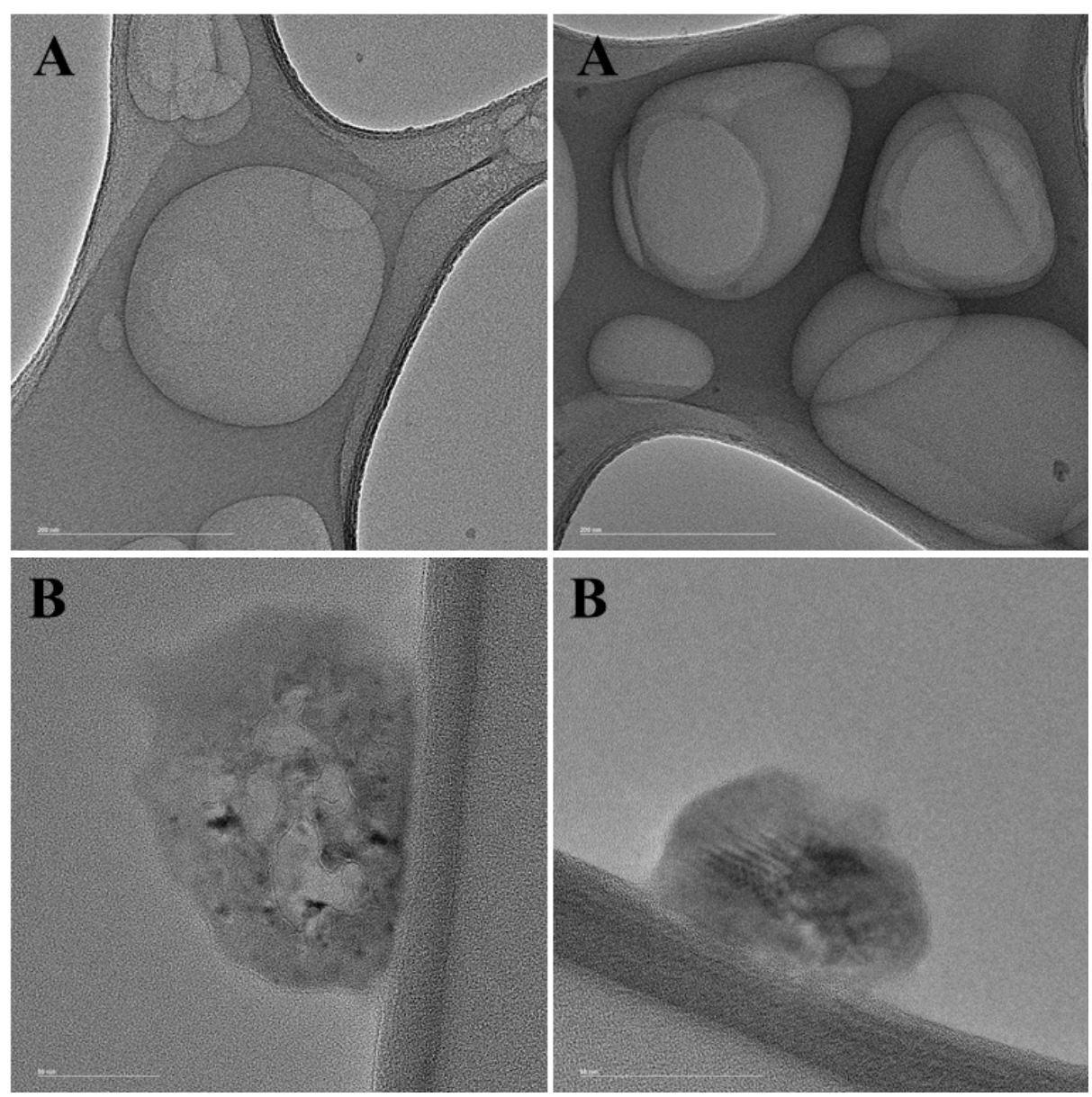

Figure S4. Transmission electron microscopy analysis of SLN (A, bar $=200 \mathrm{~nm})$ and of SLN-PA $(B$, bar $=60 \mathrm{~nm})$. $S L N=$ solid lipid nanoparticles; SLN-PA = solid lipid nanoparticles incorporated with perillyl alcohol. 